BENTHM OPEN
CrossMark
Content list available at: www.benthamopen.com/TOMICROJ/
DOI: $10.2174 / 1874285801812010107$

\title{
LETTER
}

\section{Expression of Phi11 Gp07 Causes Filamentation in Escherichia coli}

\author{
Avijit Das, Sumit Biswas and Malabika Biswas* \\ BITS Pilani, K.K.Birla Goa Campus, Zuarinagar, Goa-403726, India
}

Received: February 10, 2018

Revised: April 7, 2018

Accepted: April 8, 2018

\begin{abstract}
:
Background:

The Gp07 protein of aureophage Phi11 exhibits growth inhibitory effects when overexpressed in E. coli . The protein harbors two domains- an amino terminal Bro-like domain and a carboxy terminal Ant superfamily like KilA domain, of which the KilA domain retains the growth inhibitory effect of Gp07.
\end{abstract}

\section{Methods:}

We studied the effects exerted by the overexpression of Gp07 and its separate domains upon the growth rate as well as the morphology of the E. coli cells. Additionally, we generated a mutant of Gp07 (designated as $\Delta \mathrm{Gp} 07$ ) by deleting the first eleven amino acid residues from the amino-terminal region of $\mathrm{Gp} 07$, and studied its growth inhibitory effects upon E. coli.

\section{Results:}

Our results indicate that $\mathrm{Gp} 07, \Delta \mathrm{Gp} 07$ as well as the Carboxy-terminal region of Gp07 upon overexpression, retards the growth rate of the E. coli cells and also induces filamentation in the cells. Surprisingly, our data clearly suggests that the growth inhibition and filamentation induced by the the amino-terminal domain of Gp07 is temporal in nature.

\section{Conclusion:}

The carboxy-terminal of domain of gp07 is essential for its activity.

Keywords: Filamentation, E. coli, Drug-resistant, Therapeutic strategies, Bacteriophage, Host transcription.

\section{INTRODUCTION}

The growing incidence of drug-resistant pathogenic bacteria is a major concern today. It has now become critical to devise novel therapeutic strategies and antibacterial alternatives to combat infections caused by multi-drug resistant pathogens. Several bacteriophages have been reported to utilize the host machinery for their survival. Such bacteriophages code for certain proteins which alter some of the essential host proteins. These phage encoded proteins can either be bacteriostatic or bactericidal in nature [1]. Information about such phage encoded proteins can be instrumental in designing drugs against pathogenic bacteria [2].

Phi11 is a temperate bacteriophage (serogroup B [3] and lytic group III) which infects Staphylococcus aureus. It harbours a $43.6 \mathrm{~kb}$ [4] double stranded linear DNA genome $(\mathrm{G}+\mathrm{C}$ content of 35-37\%) [5]. Being a temperate phage, Phi11 can undergo both the lytic as well as the lysogenic mode of development. The sequence of Phi11 gp07 revealed the presence of two conserved domains- the amino terminal domain belonging to baculovirus repeated ORF[s] Bro family and the carboxy terminal domain belonging to ANT superfamily which bears homology to KilA domain [6]. The Bro proteins were proposed to be DNA-binding in nature and are involved in the regulation of viral and host

\footnotetext{
* Address correspondence to this author at the BITS Pilani, K.K.Birla Goa Campus, Zuarinagar, Goa-403726, India; Tel: 0832-2580136; E-mail: mbiswas@goa.bits-pilani.ac.in
} 
transcription, replication and chromatin structure [7, 8]. It has already been reported that bacteriophage lambda harbours a gene called the kil gene. Overexpression of the kil gene leads to inhibition of FtsZ ring formation, which in turn induces filamentation of E. coli [9].

To look into the effect of gp07 gene upon the host cells, we have cloned and overexpressed the Phi11 Gp07, its domains, as well as a truncated $\mathrm{Gp} 07(\Delta \mathrm{Gp} 07)$ as histidine-tagged variants. $\Delta \mathrm{Gp} 07$ has been generated by deletion of 11 amino acid residues present at the amino terminal region of Gp07. Overexpression of the Gp07, $\Delta \mathrm{Gp} 07$ as well as the KilA-C domain exhibited an inhibitory effect upon the cell division of $E$. coli. The Bro domain upon overexpression did exhibit some degree of toxicity; however, the inhibitory effect exerted by Gp07, $\Delta \mathrm{Gp} 07$ and the KilA-C domain expression far exceeded that of the Bro domain. This study offers a firsthand preliminary report about the cell growth inhibitory role of Phi11 gp07.

\section{MATERIALS AND METHODS}

\subsection{Bacterial Strains, Phage Strains, and Growth Conditions}

Phi11 has been grown in our laboratory according to the method of Lee and Iandolo [10]. S. aureus RN4220 was grown at $37^{\circ} \mathrm{C}$ in Trypticase soy broth [11]. E. coli BL21 (DE3) and E. coli XL1 Blue cells were grown at $37^{\circ} \mathrm{C}$ in Luria broth [12]. Appropriate antibiotics were added to the growth media as required.

\subsection{Molecular Biological Techniques}

Isolation of Phi1 1 chromosomal DNA was carried out by some modification of prescribed method [10]. All DNA manipulations such as plasmid DNA isolation, polymerase chain reaction, restriction enzyme digestion of DNA, ligation of DNA fragments, transformation were carried out according to standard procedure [12]. Sequencing of all Phil1 DNA inserts (amplified by PCR) were performed in UDSC (New Delhi, India). Standard methods were employed to estimate the amount of protein; SDS-PAGE, polyacrylamide gel staining were also carried out by standard procedure [13].

\subsection{Bioinformatics Analysis of Gp07}

Genome databases in NCBI (http://www.ncbi.nlm.nih.gov/) and Pfam (http://pfam.sanger.ac.uk/) were used for bioinformatics analysis of Gp07. EMBOSS programs (https://www.ebi.ac.uk/Tools/emboss/) were used for different bioinformatics analyses like molecular weight determination, charge and presence of different amino acid. Sequence similarity search was carried out by BLAST server (http://www.blast.ncbi.nlm.nih.gov/blast/Blast.cgi). The search for Phi11 gp07 gene was carried out using BLASTP in different databases in Caudovirales order and $50 \%$ or more identity was taken as the threshold [14]. Sequences similar to the gp07 of Phil1 were detected from different non-redundant (NR) protein sequence databases by BLAST (blastp) program 2.2.32+. Alignment of full-length Gp07 protein was performed by Clustal Omega program 1.2.1 (http:/www.ebi.ac.uk/Tools/msa/clustalo/). Using all the proteins which shared 50\% identity to the Phil1 Gp07, a dendrogram was constructed using ClustalW2 Phylogeny program (https://www.ebi.ac.uk/Tools/phylogeny/clustalw2_phylogeny/) with neighbor-joining method.

\subsection{Cloning of gp07, Its Domains and Truncated Gp07( $\Delta \mathrm{Gp07})$}

To clone Phi11 Gp07, we employed a polymerase chain reaction with DreamTaq DNA Polymerase from ThermoFisher Scientific using primers C-Gp07-F and C-Gp07-R (Table 1). The template used was Phil1 genomic DNA. The product obtained was $825 \mathrm{bp}$ in size and was cloned into pGEM-T Easy vector (Table 2) according to the manufacturer's protocol (www.promega.com/protocols/). The recombinant pGEM-T Easy vector was transformed into competent E. coli XL1 Blue cells. The recombinant pGEM-T Easy vector carrying no mutation in the gp07 (as confirmed by DNA sequencing) was chosen for further work. gp07 was further subcloned into pET28a (Table 2) and designated as Gp07. This cloning protocol has included ten extra amino acid residues (including six histidine residues) at the carboxy terminal end of the putative Gp07 protein.

Table 1. Primer used in this study to express the Gp07, rNTD, rCTD and $\Delta$ Gp07.

\begin{tabular}{|c|c|c|}
\hline Name & Sequence(5'-3' ${ }^{\prime}{ }^{\prime}$ & Purpose \\
\hline C-gp07-F & AAACCATGGGAATGTGGGTGTTGAGGAAAAAGGAGG & Forward primer for synthesis of Gp07 and rNTD \\
\hline C-gp07-R & AAACTCGAGCGCTCCCCCTAAATTAGCTTCATAAC & Reverse primer for Synthesis of Gp07 and $\Delta$ Gp07 \\
\hline C-Bro-R & AAACTCGAGGTCTGGATCTTTTAATGTTTGTTCAATTACATTG & Reverse primer for the synthesis of rNTD \\
\hline
\end{tabular}


(Table 1) contd.....

\begin{tabular}{|c|c|c|}
\hline Name & Sequence $\left(5^{\prime}-3^{\prime}\right)^{\#}$ & Purpose \\
\hline N-KilAC-F & AAACATATGTACATCATTACAGTGTTGACTGAGTATAAGAAAG & Forward primer for the synthesis of rCTD \\
\hline N-gp07-R & AAACTCGAGTTACGCTCССССТАAATTAGCTTCATAАCC & Reverse primer for the synthesis of rCTD \\
\hline C- $\Delta$ gp07-F & AAACCATGGAAATGCAAGCATTACAAACATTTAATTTTAAAGAGC & Forward primer for synthesis of $\Delta \mathrm{Gp} 07$ \\
\hline
\end{tabular}

Table 2. Plasmid used in this study and their derivatives.

\begin{tabular}{|c|c|c|}
\hline Plasmids & Source & Description \\
\hline pGEM-T Easy & Promega & $a m p^{\mathrm{r}}, l a c Z$, cloning vector \\
\hline pET28a & Novagen & kan $^{\mathrm{r}}$, T7 lac, His-tag, expression vector \\
\hline pGp07-T & This study & gp07 cloned in pGEM-T Easy vector \\
\hline pGp07 & This study & gp07 cloned in pET28a \\
\hline prNTD-T & This study & rNTD cloned in pGEM-T Easy vector \\
\hline prNTD & This study & rNTD domain cloned in pET28a \\
\hline prCTD-T & This study & rCTD domain cloned in pGEM-T Easy vector \\
\hline prCTD & This study & rCTD domain cloned in pET28a \\
\hline $\mathrm{p} \Delta \mathrm{Gp} 07-\mathrm{T}$ & This study & $\Delta \mathrm{Gp} 07$ cloned in pGEM-T Easy vector \\
\hline $\mathrm{p} \Delta \mathrm{Gp} 07$ & This study & $\Delta \mathrm{Gp} 07$ domain cloned in pET28a \\
\hline
\end{tabular}

Similarly $\Delta \mathrm{Gp} 07$ (generated by deletion of 11 amino acid residues present at the amino terminal region of Gp07), Bro-N(rNTD) and KilA-C(rCTD) domains were PCR amplified from Phi11 genomic DNA using the primers C- $\Delta$ Gp07F, C-gp07-R; C-gp07-F, C-Bro-R and N-KilAC-F, N-gp07-R respectively (Table 2). The resulting PCR products of $792 \mathrm{bp}(\Delta \mathrm{Gp} 07), 420 \mathrm{bp}(\mathrm{rNTD})$ and $405 \mathrm{bp}(\mathrm{rCTD})$ were cloned into pGEM-T Easy vector (Table 1), sequenced and further sub-cloned into pET28a (Table 1). All the recombinant constructs were transformed into E. coli BL21(DE3) cells (Novagen, USA) and healthy transformants (carrying no mutation) were selected for overexpression.

\subsection{Overexpression Assays of Gp07, Its Domains and $\Delta \mathrm{Gp07}$ in E. coli}

E. coli cells harbouring Gp07, rNTD, rCTD and $\Delta \mathrm{Gp} 07$ were separately grown in LB (with $50 \mu \mathrm{g} / \mathrm{ml}$ kanamycin), overnight at $37^{\circ} \mathrm{C}$ with shaking. At $\sim 12-14 \mathrm{~h}$, these cultures were subcultured to $\mathrm{OD}_{600}$ of $\sim 0.05$ in $\mathrm{LB}$ (with $50 \mu \mathrm{g} / \mathrm{ml}$ kanamycin) followed by induction with $0.5 \mathrm{mM}$ IPTG. Following induction, $\mathrm{OD}_{600}$ of the cultures were measured at 30 minutes. This was followed by $\mathrm{OD}_{600}$ measurements every 1 hour for 8 hours. The entire procedure was repeated three times and the mean values and the standard errors were calculated. The CI repressor protein of Phi11 [15] was used as a negative control.

\subsection{Examination of cell morphology of $E$. coli (Harbouring Gp07, rNTD, rCTD or $\Delta$ Gp07) Using Phase-Contrast and Fluorescence Microscopy}

Following induction with IPTG, cells overexpressing either Gp07, rNTD, rCTD or $\Delta \mathrm{Gp} 07$ (were harvested at two different time point $(5 \mathrm{~h}$ and $8 \mathrm{~h}$ ) and washed with $0.9 \%$ sterile $\mathrm{NaCl}$ solution. The washed cells were resuspended in saline, spread on a clean glass slide, air dried at room temperature and then fixed with methanol for 5 minutes at room temperature. The fixed cells were thoroughly washed with sterile distilled water, dried at room temperature, and then $10 \mu 1$ of poly-L-lysine ( $5 \mu \mathrm{g} / \mathrm{ml}$ of distilled water) was spread over the sample (16).

To study the nucleoid structures formed in the E. coli cells (expressing either Gp07, rNTD, rCTD, $\Delta \mathrm{Gp} 07$ or none), the desired samples were stained with DAPI solution [2-(4-Amidinophenyl)-6-indolecarbamidine dihydrochloride, 4', 6Diamidino-2-phenylindole dihydrochloride] (Sigma-Aldrich Chemicals Pvt Limited) (10ul; $5 \mathrm{ug} / \mathrm{ml}$ of saline), which binds specifically to DNA [16]. The cells were observed through an Olympus IX51 inverted microscope oil immersion objective (100X), combining the phase-contrast system and the fluorescence system (a U-LH100HG apparatus) in a dark room. When the light of a halogen lamp was reduced to an appropriate level, the fluorescent nucleoid structures and cell shape were clearly visible at the same time. The microscope was also equipped with a $\operatorname{ProgRes}{ }^{\circledR}$ CT3 camera (Jenoptik, USA). Photographs were captured and analyzed by ProgRes ${ }^{\circledR}$ CapturePro 2.8.8 software. The CI repressor protein of Phil1 was used as a negative control. 


\subsection{Examination of E. coli Cell Morphology with Scanning Electron Microscopy (SEM)}

To prepare samples for scanning electron microscopy, overnight cultures of $E$. coli cells carrying gp07, its domains and $\Delta \mathrm{Gp} 07$ (expressing either Gp07, rNTD, rCTD or $\Delta \mathrm{Gp} 07$ ) were separately allowed to grow to $\mathrm{OD}_{600} 0.05$ in fresh LB at $37^{\circ} \mathrm{C}$. Wild type E. coli as well as E. coli overexpressing Phi11 CI were used as controls. The cells were induced with $0.5 \mathrm{mM}$ IPTG and cultured at $37^{\circ} \mathrm{C}, 120 \mathrm{rpm}$ shaking for another $8 \mathrm{~h}$. Cells were then harvested by centrifugation for $10 \mathrm{~min}$ at $7500 \mathrm{~g}$ followed by washing with $1 \mathrm{X}$ PBS ( $\mathrm{pH} 7)$ twice. The final cell pellets were re-suspended in appropriate volume of 1X PBS and thinly smeared on clean cover-slips. The prepared cover-slips were kept for air drying. The dried cover slips were then washed three times with 1 X PBS and the cells were pre-fixed with $3 \%$ glutaraldehyde (in 1X PBS) for $1 \mathrm{hr}$ at room temperature. The excess glutaraldehyde was removed by washing the cells, three times, with $1 \mathrm{X}$ PBS. The cells were then treated with $1 \% \mathrm{OsO}_{4}$ at $4{ }^{\circ} \mathrm{C}$, and left overnight. Following this, the cells were again washed three times with $1 \mathrm{X}$ PBS at room temperature. Cells were then dehydrated using a series of ethanol solutions $(10 \%, 30 \%, 50 \%, 70 \%$ and $90 \%, 5 \mathrm{~min}$ each) and finally transferred to $100 \%$ ethanol for $10 \mathrm{~min}$. To completely dehydrate the cells the prepared slides were transferred to a CPD chamber (Leica EM CPD300). The specimens were placed onto foil which was glued onto a metal specimen holder after the CPD completion. The specimens were coated by gold-palladium mixture at $5 \mathrm{~nm}$ thickness using Leica EM ACE200. The SEM images of cells were obtained using a FEI Quanta FEG 250 Scanning electron microscope.

\section{RESULT}

\subsection{Pfam Analysis of Gp07}

Pfam (http://pfam.xfam.org) was used for full length protein sequence analyses. In Phi11 genome, amino acid sequence analysis by Pfam indicated that the locus tag "phi11_07" [ORF7, which was predicted as a Gp07] exists adjacent to the Cro-repressor (ORF6) [17]. The Gp07 protein consists of two conserved domains, an amino terminal domain (NTD) and the carboxy terminal domain (CTD). Out of the 274 amino acids of Gp07, the NTD ranges from 25 th to 118 th amino acids and belongs to baculovirus repeated ORF(s) Bro-N family (6). The CTD ranges from 160th to 263 rd amino acid residues of Gp07 and belongs to KilA-C domain under ANT superfamily Fig. (1A). KilA-C was initially reported as the carboxy terminal domain of phage PI KilA (7). According to Pfam analysis, the E-value for Phi11 Bro-N is 1.5e-27 and 5.4e-30 for KilA-C domain. Bro gene (5 members) has been reported in Bombyx mori nucleopolyhedrovirus (BmNPV), a double stranded virus infecting lepidopterans (6). Further, there are reports of the existence of bro gene homologues in transposons, bacteriophages and probacteriophages [8, 18, 19]. The Bro proteins are regulatory proteins involved in regulating transcription, replication in certain viruses and their host organisms.

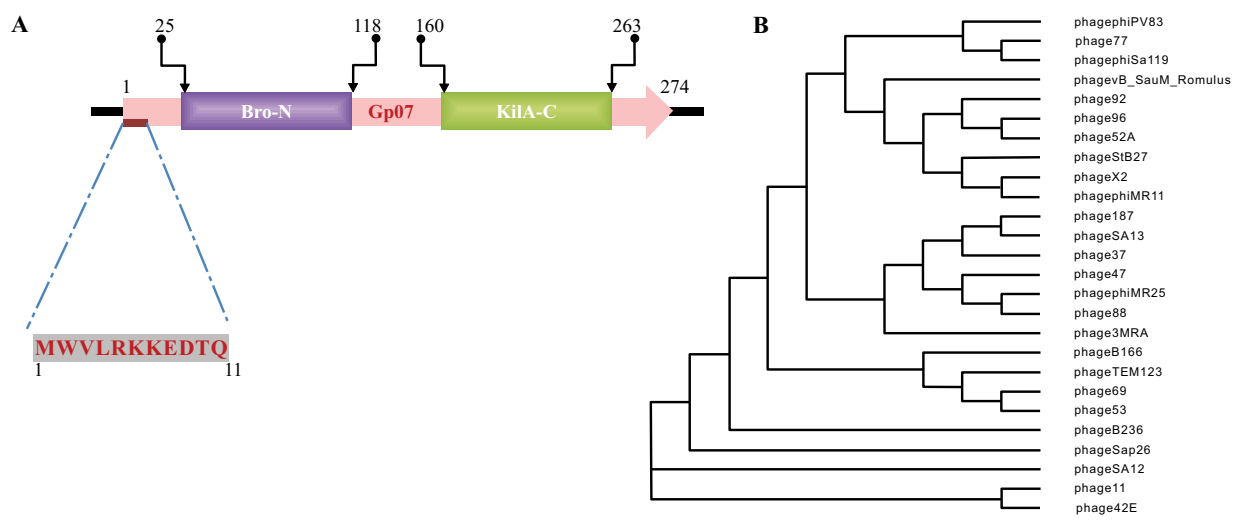

Fig. (1). Domain organization of Gp07. (A) Pfam analysis indicates that Gp07 harbours two domains- the amino terminal Bro domain and carboxy terminal KilA domain; the first eleven unique amino acids are coloured gray. (B) Phylogenetic analysis of Phil1 Gp07 has been aligned with ClustalO (See Materials and Methods for details) by neighbour-joining method. The Phil1 is evolutionary closely related with phage $42 \mathrm{E}$.

\subsection{Gp07 of Phi11 Belongs to the Caudovirales}

According to International Committee on Taxonomy of Viruses (ICTV) classification, Caudovirales (the bacteriophages that have tails) is a taxonomic order within the kingdom Virus. There are at least 1442 phages in this order with complete genome sequence known to us. By BLASTP search of non-redundant (NR) databases in Caudovirales order, it was observed that apart from the conserved residues, the first eleven amino acids of Phil1 Gp07 
protein are extremely unique Fig. (1A). These eleven amino acid residues are absent in all other proteins harbouring KilA-C and Bro-N domains, in Caudovirales order as well as outside the Caudovirales order Fig. (2). All this twenty-six phages (vide Fig. 2) belong to the Myoviridae family of viral systems. The neighbor-joining phylogenetic analyses revealed that the phage most closely related evolutionarily to phage Phi11 is Staphylococcal phage 42E Fig. (1B). It was reported that bro-like gene family is widespread among large double-stranded DNA viruses of invertebrates and bacteria [8]. Additionally, other reports revealed shuffling of domains which leads to different patterns of gene organizations [7].

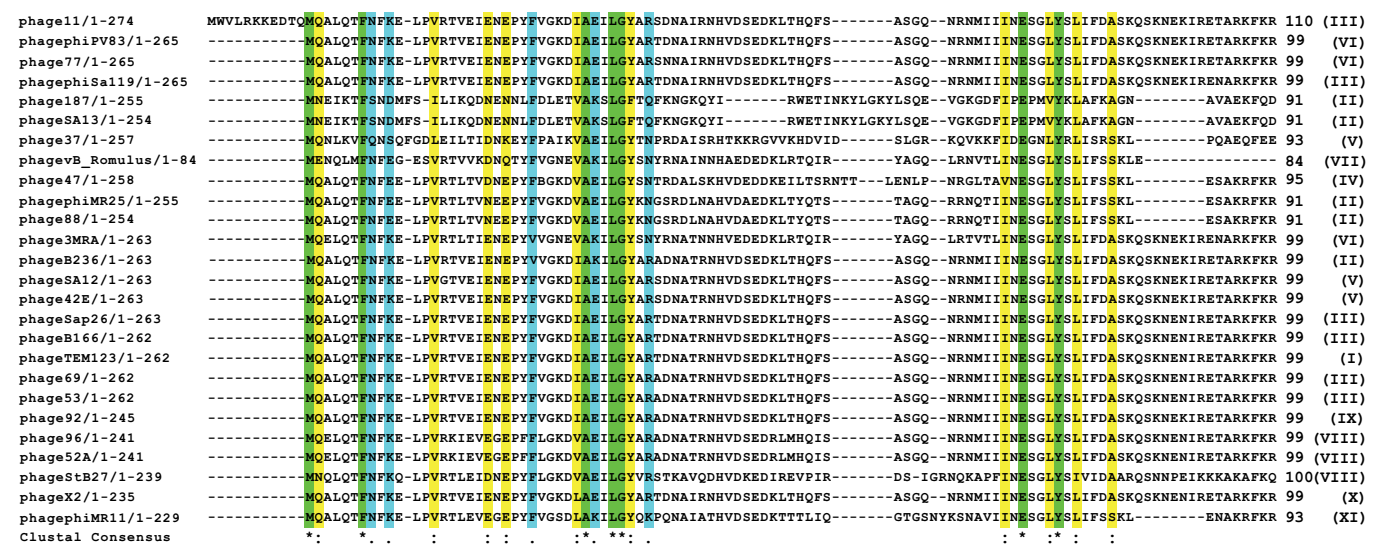

Fig. (2). Sequence analysis of the full-length protein of some phages in Caudovirales. Sequences are designated by their phage name and followed by protein length. Phi11 Gp07 has been aligned with ClustalO (See Materials and Methods for details). The coloring reflects the conservation profile at clustal consensus of amino acids. '*' identical residues (M,F,A,L,G,E,Y), all shaded green. ' : ' highly conserved residues (Q,V,I,E,N,D,Y,F) shaded yellow. ' .' weakly conserved residues (S,D,E,F,V,R,Q,N,K) shaded turquoise. Phage Phil1 unique residues region (MWVLRKKEDTQ) all coloured gray.

\subsection{Inhibition of Cell Growth by Expression of Gp07, Its Domains and $\Delta \mathrm{Gp} 07$}

E. coli cells harbouring either $\mathrm{Gp} 07$, rCTD or $\Delta \mathrm{Gp} 07$ (overexpressions were confirmed by SDS-12\% PAGE, Fig. 3), upon induction by $0.5 \mathrm{mM}$ IPTG at $37^{\circ} \mathrm{C}$ for $5 \mathrm{~h}$, showed a rapid inhibition in growth rate Fig. (4). This data is indicative of the growth inhibitory nature of $\mathrm{Gp} 07$. However, it was observed that there was a minor increase in $\mathrm{OD}_{600}$ of the cells after approximately 6 hours of induction of Gp07, rCTD or $\Delta \mathrm{Gp} 07$ Fig. (4). On the other hand, E. coli cells harbouring rNTD (overexpression was confirmed by SDS- $12 \%$ PAGE, Fig. 3) upon induction by $0.5 \mathrm{mM} \mathrm{IPTG}$ at $37^{\circ} \mathrm{C}$ for $3 \mathrm{~h}$ also showed inhibition in growth rate. However, in this case, the growth inhibition was much lower than that of Gp07, rCTD or $\triangle \mathrm{Gp} 07$ Fig. (4). More interestingly, in this case, resumption of growth by the induced cells occurred earlier than that in case of $\mathrm{Gp} 07, \mathrm{rCTD}$ or $\triangle \mathrm{Gp} 07$ and there was a substantial increase in the optical density $\left(\mathrm{OD}_{600}\right)$ at the end of $5 \mathrm{~h}$. In case of the negative control, CI, there was no significant change in the OD of the overexpressing cells as compared to the wild type cells.

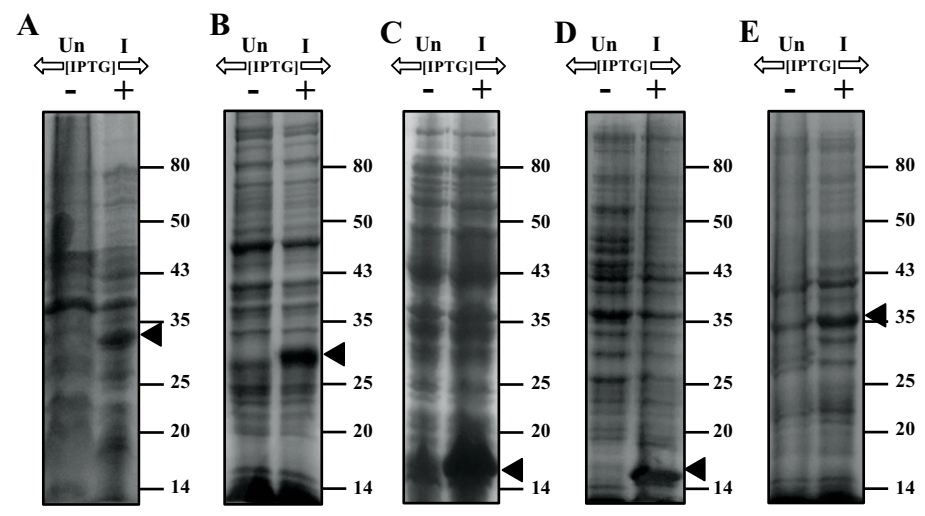

Fig. (3). Overexpression of Gp07, its domains (rNTD, rCTD), $\Delta$ gp07 and a control protein in $E$. coli. Overexpression of the recombinant proteins (induced with $0.5 \mathrm{mM}$ IPTG for $2 \mathrm{hrs}$ at $37^{\circ} \mathrm{C}$ ) were analysed on SDS-12\%-PAGE. (A) Overexpression of Gp07 (B) Overexpression of $\triangle \mathrm{Gp} 07$ (C) Overexpression of rNTD; (D) Overexpression of rCTD; (E) Overexpression of control protein. Arrowheads indicate the overexpressed protein. Un indicates uninduced cellular extract; I indicates induced cellular extract. 


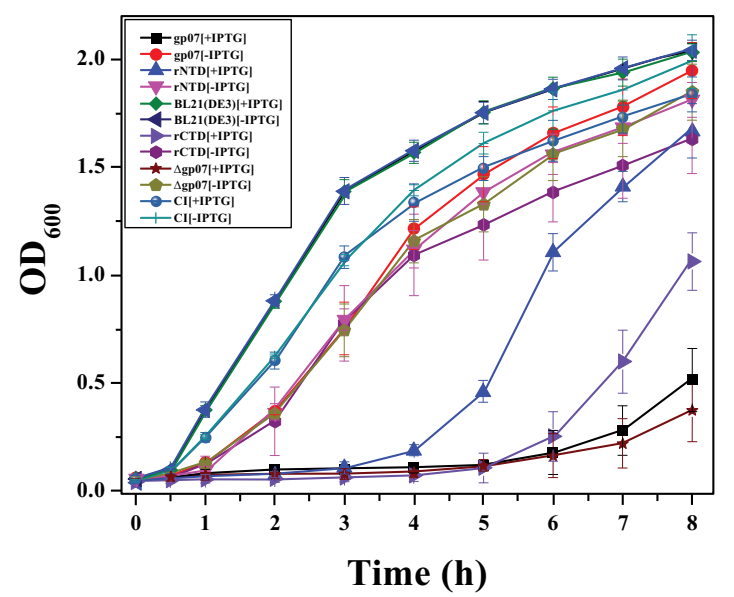

Fig. (4). Effect of Gp07, its domains and $\Delta \mathrm{Gp07}$ upon the growth of $\boldsymbol{E}$. coli. Overexpression of Phi11 Gp07, rCTD as well as the $\triangle \mathrm{Gp} 07$ inhibited growth of the host cells. Overexpression of rNTD initially repressed host cell growth but resumption of cell growth was seen after a few hours. The overexpressed control protein (CI) had no effect upon the growth of $E$. coli cells. All experiments were performed in triplicate. The standard error of the mean was used to calculate the error bars. In case of those points where the experimental variations are too small, the error bars are not visible.

\subsection{Microscopic Observation of $E$. Coli Cells Upon Overexpression of Gp07, Its Domains and $\Delta \mathrm{Gp07}$}

E. coli cells (harbouring no plasmid) and E. coli cells harbouring Gp07, induced with $0.5 \mathrm{mM}$ IPTG were examined under phase contrast microscope as well as SEM. It was observed that, the host cells carrying Gp07 upon induction became filamentous Figs. (5E , 5G and 6C). Moreover, irregular multiple nucleoid structures could be observed upon staining of the induced cells with DAPI Figs. (5F and $\mathbf{5 H}$ ). This suggests that normal DNA replication progressed in the cells. The filamentation was not reversible in case of $E$. coli cells overexpressing Gp07 Figs. (5E, 5G and 6C). Similar results were also observed in case of $E$. coli cells harbouring $\mathrm{rCTD}$ and $\Delta \mathrm{Gp} 07 \mathrm{Fig}$. (5). In case of rNTD however, the filamentation was reversed at the end of $8 \mathrm{~h}$ as is evident from Figs. (I/5K and 6D). Examination of the induced $E$. coli cells harbouring rNTD by phase contrast microscopy as well as SEM showed an increased number of E. coli cells with normal morphology at the end of $8 \mathrm{~h}$ Figs. (5K and 6D). This further strengthens our observation that compared to rNTD domain, the rCTD domain is essential for the growth inhibitory effect of Gp07. In its absence, the rNTD alone cannot retain this activity of Gp07. The negative control, CI, had no effect on the morphology of the host cells Figs. $(5 \mathrm{C}, 5 \mathrm{D}$ and $6 \mathrm{~B})$.

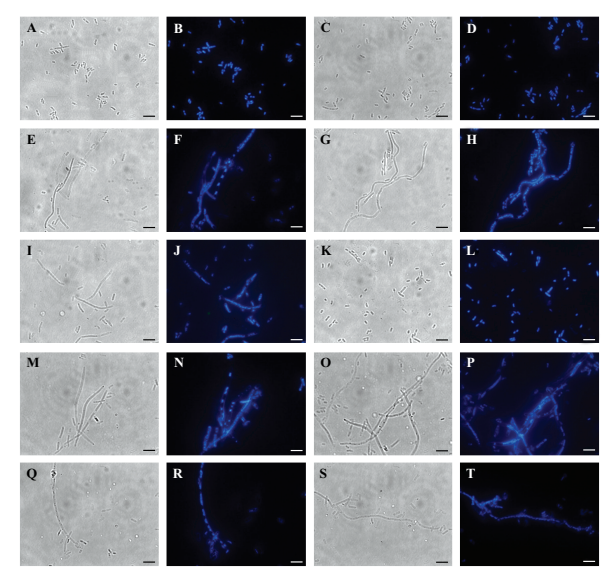

Fig. (5). Effect of overexpression of Gp07, its domains and $\Delta$ Gp07 on the morphology of host cell. (A) Morphology of wild type host cells (E. coli) under microscope at 100X magnification. (C) Morphology of E. coli cells overexpressing the control protein. (E,I,M,Q) Morphology of E. coli cells overexpressing Gp07, rNTD, rCTD and $\Delta \mathrm{Gp} 07$ respectively at 5h, as observed by phase contrast microscopy. (G,K,O,S) Morphology of E. coli cells overexpressing Gp07, rNTD, rCTD and $\Delta \mathrm{Gp} 07$ respectively at 8h, as observed by phase contrast microscopy. (B) DAPI stained normal host cells (E. coli BL21 DE3 not carrying any recombinant DNA) under fluorescence microscope. (D) DAPI stained E.coli cells overexpressing the control protein. (F,J,N,R) DAPI stained E.coli cells overexpressing Gp07, rNTD, rCTD and $\Delta \mathrm{Gp} 07$ respectively at 5h, under fluorescence microscope. (H,L,P,T) DAPI stained E. coli cells overexpressing Gp07, rNTD, rCTD and $\Delta \mathrm{Gp} 07$ respectively at $8 \mathrm{~h}$, under fluorescence microscope. All the scale bars are $5 \mu \mathrm{m}$. 

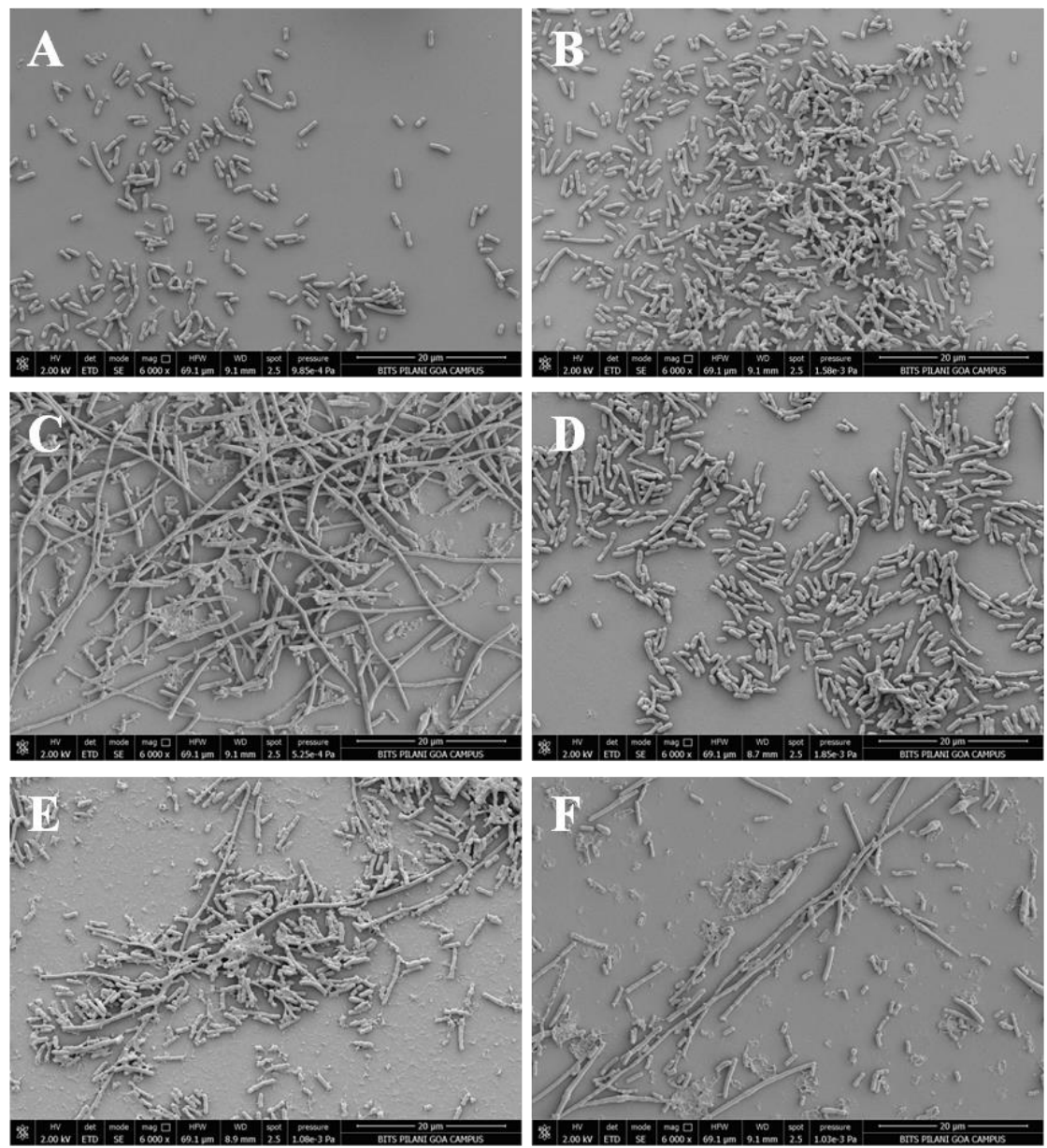

Fig. (6). Scanning electron micrographs of Wild type (WT), Control protein, Gp07, rNTD, rCTD and $\Delta$ Gp07 expression in $E$. coli. (A) Wild type (WT), (B) Control protein (C) Gp07, (D) rNTD, (E) rCTD, (F) $\Delta$ Gp07; all scale bars are $20 \mu \mathrm{m}$.

\section{DISCUSSION}

Our preliminary work showed that overexpression of Gp07, $\triangle \mathrm{Gp} 07$, as well as its domain KilA-C (rCTD) significantly inhibited the growth of $E$. coli following induction with IPTG. Similar observations have already been reported in host cells expressing the icd gene of P1 [20], whereby, E. coli cells expressing the Icd protein of bacteriophage P1, become filamentous in nature. There have also been reports that the Rac prophage (21) of E. coli harbours a gene called kil which codes for a 73 amino acid protein. The overexpression of this kil gene was shown to block cell division resulting in filamentation of the host cell. It has further been reported that this inhibition is relieved by excess FtsZ [21]. Studies on the Kim (Qin) prophage [22] also indicate the inhibition of divisome formation in $E$. coli. The kil gene of bacteriophage lambda has also been reported to induce filamentation in host cells [9]. Haeusser et al., have already reported that cell division in $E$. coli host cells are blocked by the Kil protein of bacteriophage $\lambda$. The Kil protein possibly ablates the FtsZ rings in E. coli, thereby blocking cell division. The block can however be inhibited by an abundance of FtsZ [9].

Our other observation in E. coli cells overexpressing Gp07, $\triangle \mathrm{Gp} 07$ as well as its domain KilA-C (rCTD), was the very slight increase in the optical density of the cells measured at $600 \mathrm{~nm}$ from 5-6 h following induction. We initially assumed that the growth inhibitory effect exerted by $\mathrm{Gp} 07$ might be temporal in nature and hence the slight increase in OD; however, cell morphology studies indicated that the cells upon Gp07, $\Delta \mathrm{Gp} 07$ and KilA-C expression became filamentous in nature, which is an indication of inhibition of cell division. This slight increase in the OD value can be attributed to the increase in the length of the filamentous cells and not necessarily due to the resumption of cell growth. Further, CFU analysis of $E$. coli cells indicated that there was no significant increase in the number of CFU after overexpression of Gp07 in E. coli, at different time intervals (data not shown).

Analysis of the amino acid sequence of Gp07 further indicates that the first eleven amino acids of Phi11 Gp07 protein are extremely unique Figs. (1A and $\mathbf{2}$ ). To check if the eleven amino acid residues had any role in the growth 
inhibitory effect of Gp07, we deleted these amino acids and generated the mutant, $\Delta \mathrm{Gp} 07$. It is interesting to note that $\Delta \mathrm{Gp} 07$ retained the growth inhibitory effect displayed by full- length Gp07. Thus we can assume that the first eleven amino acids of Phil1 Gp07 protein do not play any role in its growth inhibitory effect. Further bioinformatics analysis of Gp07 showed that the two identified domains, Bro-N and KilA-C are widely spread and present in different organisms. Considering our cell growth kinetics experiments, studies on cell morphology with phase-contrast and fluorescence microscopy as well as SEM data of Gp07 and its domains, it is clear that the carboxy terminal domain of Gp07 (KilA-C domain) is more important for its growth inhibitory function in E. coli. In case of the Bro-N domain, the data clearly suggests that the growth inhibition induced by the Bro-N domain alone, is temporal in nature.

\section{CONCLUSION}

Taken together, our results indicate three things: i. Gp07 and $\Delta \mathrm{Gp} 07$ exert a growth inhibitory effect upon $E$. coli cells, ii. The KilA-C domain of Gp07 is essential for its activity, and iii. The Bro-N domain is not essential for the growth inhibitory effect; moreover, the growth inhibition of $E$. coli induced by the Bro domain is temporal in nature.

\section{ETHICS APPROVAL AND CONSENT TO PARTICIPATE}

Not applicable.

\section{HUMAN AND ANIMAL RIGHTS}

No Animals/Humans were used for studies that are base of this research.

\section{CONSENT FOR PUBLICATION}

Not applicable.

\section{CONFLICT OF INTEREST}

The author confirms that this article content has no conflict of interest.

\section{ACKNOWLEDGEMENTS}

Not applicable.

\section{REFERENCES}

[1] Sau S, Chattoraj P, Ganguly T, Chanda PK, Mandal NC. Inactivation of indispensable bacterial proteins by early proteins of bacteriophages: implication in antibacterial drug discovery. Curr Protein Pept Sci 2008; 9(3): 284-90. [http://dx.doi.org/10.2174/138920308784533970] [PMID: 18537683]

[2] Liu J, Dehbi M, Moeck G, et al. Antimicrobial drug discovery through bacteriophage genomics. Nat Biotechnol 2004; 22(2): 185-91 [http://dx.doi.org/10.1038/nbt932] [PMID: 14716317]

[3] Bächi B. Physical mapping of the BgII, BglII, PstI and EcoRI restriction fragments of staphylococcal phage phi 11 DNA. Mol Gen Genet 1980; 180(2): 391-8. [http://dx.doi.org/10.1007/BF00425853] [PMID: 6258026]

[4] Iandolo JJ, Worrell V, Groicher KH, et al. Comparative analysis of the genomes of the temperate bacteriophages phi 11 , phi 12 and phi 13 of Staphylococcus aureus 8325. Gene 2002; 289(1-2): 109-18. [http://dx.doi.org/10.1016/S0378-1119(02)00481-X] [PMID: 12036589]

[5] Brown DT, Brown NC, Burlingham BT. Morphology and physical properties of Staphylococcus bacteriophage P11-M15. J Virol 1972; 9(4): 664-71. [PMID: 4112070]

[6] Zemskov EA, Kang W, Maeda S. Evidence for nucleic acid binding ability and nucleosome association of Bombyx mori nucleopolyhedrovirus BRO proteins. J Virol 2000; 74(15): 6784-9.

[http://dx.doi.org/10.1128/JVI.74.15.6784-6789.2000] [PMID: 10888617]

[7] Iyer LM, Koonin EV, Aravind L. Extensive domain shuffling in transcription regulators of DNA viruses and implications for the origin of fungal APSES transcription factors Genome biology 2002; 3(3) Research0012.

[8] Bideshi DK, Renault S, Stasiak K, Federici BA, Bigot Y. Phylogenetic analysis and possible function of bro-like genes, a multigene family widespread among large double-stranded DNA viruses of invertebrates and bacteria. J Gen Virol 2003; 84(Pt 9): 2531-44. [http://dx.doi.org/10.1099/vir.0.19256-0] [PMID: 12917475]

[9] Haeusser DP, Hoashi M, Weaver A, et al. The Kil peptide of bacteriophage $\lambda$ blocks Escherichia coli cytokinesis via ZipA-dependent inhibition of FtsZ assembly. PLoS Genet 2014; 10(3): e1004217. 
[http://dx.doi.org/10.1371/journal.pgen.1004217] [PMID: 24651041]

[10] Lee CY, Iandolo JJ. Structural analysis of staphylococcal bacteriophage phi 11 attachment sites. J Bacteriol 1988; 170(5): 2409-11 [http://dx.doi.org/10.1128/jb.170.5.2409-2411.1988] [PMID: 2966144]

[11] Lee CY, Iandolo JJ. Integration of staphylococcal phage L54a occurs by site-specific recombination: structural analysis of the attachment sites. Proc Natl Acad Sci USA 1986; 83(15): 5474-8. [http://dx.doi.org/10.1073/pnas.83.15.5474] [PMID: 2942938]

[12] Russell DW, Sambrook J. Molecular Cloning: A Laboratory Manual. New York, USA: Cold Spring Harbor Laboratory Press 2001.

[13] Ausubel FM, Brent R. Current Protocols in Molecular Biology. USA: John Wiley \& Sons, Inc. 1998.

[14] Altschul SF, Gish W, Miller W, Myers EW, Lipman DJ. Basic local alignment search tool. J Mol Biol 1990; $215(3)$ : 403-10. [http://dx.doi.org/10.1016/S0022-2836(05)80360-2] [PMID: 2231712]

[15] Das M, Ganguly T, Chattoraj P, et al. Purification and characterization of repressor of temperate S. aureus phage phi11. J Biochem Mol Biol 2007; 40(5): 740-8 [PMID: 17927908]

[16] Hiraga S, Niki H, Ogura T, et al. Chromosome partitioning in Escherichia coli: novel mutants producing anucleate cells. J Bacteriol 1989; 171(3): 1496-505. [http://dx.doi.org/10.1128/jb.171.3.1496-1505.1989] [PMID: 2646284]

[17] Das A, Biswas M. Changes in the functional activity of phi11 cro protein is mediated by various ions. Protein J 2016; $35(6)$ : 407-15. [http://dx.doi.org/10.1007/s10930-016-9684-8] [PMID: 27812887]

[18] Riedel HD, Heinrich J, Heisig A, Choli T, Schuster H. The antirepressor of phage P1. Isolation and interaction with the C1 repressor of P1 and P7. FEBS Lett 1993; 334(2): 165-9.

[http://dx.doi.org/10.1016/0014-5793(93)81705-5] [PMID: 8224242]

[19] Ravin NV, Svarchevsky AN, Dehò G. The anti-immunity system of phage-plasmid N15: identification of the antirepressor gene and its control by a small processed RNA. Mol Microbiol 1999; 34(5): 980-94. [http://dx.doi.org/10.1046/j.1365-2958.1999.01658.x] [PMID: 10594823]

[20] Riedel HD, Heinrich J, Schuster H. Cloning, expression, and characterization of the icd gene in the immI operon of bacteriophage P1. J Bacteriol 1993; 175(10): 2833-8. [http://dx.doi.org/10.1128/jb.175.10.2833-2838.1993] [PMID: 8491703]

[21] Conter A, Bouché JP, Dassain M. Identification of a new inhibitor of essential division gene ftsZ as the kil gene of defective prophage Rac. J Bacteriol 1996; 178(17): 5100-4.

[http://dx.doi.org/10.1128/jb.178.17.5100-5104.1996] [PMID: 8752325]

[22] Yang S, Pei H, Zhang X, et al. Characterization of DicB by partially masking its potent inhibitory activity of cell division. Open Biol 2016; 6(7): 160082.

[http://dx.doi.org/10.1098/rsob.160082] [PMID: 27466443]

\section{(C) 2018 Das et al.}

This is an open access article distributed under the terms of the Creative Commons Attribution 4.0 International Public License (CC-BY 4.0), a copy of which is available at: (https://creativecommons.org/licenses/by/4.0/legalcode). This license permits unrestricted use, distribution, and reproduction in any medium, provided the original author and source are credited. 